\title{
Skills of different mesoscale models over Indian region during monsoon season: Forecast errors
}

\author{
Someshwar Das ${ }^{1,2, *}$, Raghavendra Ashrit ${ }^{1}$, Gopal Raman Iyengar ${ }^{1}$, Saji Mohandas ${ }^{1}$, \\ M Das Gupta ${ }^{1}$, John P George ${ }^{1}$, E N Rajagopal ${ }^{1}$ and Surya Kanti Dutta ${ }^{1}$ \\ ${ }^{1}$ National Center for Medium Range Weather Forecasting, Noida, India. \\ ${ }^{2}$ Present Address: SAARC Meteorological Research Centre, Dhaka, Bangladesh. \\ *e-mail:somesh07@yahoo.com
}

Performance of four mesoscale models namely, the MM5, ETA, RSM and WRF, run at NCMRWF for short range weather forecasting has been examined during monsoon-2006. Evaluation is carried out based upon comparisons between observations and day-1 and day-3 forecasts of wind, temperature, specific humidity, geopotential height, rainfall, systematic errors, root mean square errors and specific events like the monsoon depressions.

It is very difficult to address the question of which model performs best over the Indian region? An honest answer is 'none'. Perhaps an ensemble approach would be the best. However, if we must make a final verdict, it can be stated that in general, (i) the WRF is able to produce best All India rainfall prediction compared to observations in the day-1 forecast and, the MM5 is able to produce best All India rainfall forecasts in day-3, but ETA and RSM are able to depict the best distribution of rainfall maxima along the west coast of India, (ii) the MM5 is able to produce least RMSE of wind and geopotential fields at most of the time, and (iii) the RSM is able to produce least errors in the day- 1 forecasts of the tracks, while the ETA model produces least errors in the day-3 forecasts.

\section{Introduction}

Mesoscale models are important for the simulation and prediction of high impact severe weather systems. Such models remain important for an operational numerical weather prediction centre, because they can be run at very high resolution on a nested grid with a wide variety of options for the parameterization of physical processes. The global models do not have such privileges and, they are very expensive to run at high resolutions. Moreover, at finer resolution the mesoscale models are also capable of assimilating large amounts of high resolution observations available from present day satellites and Doppler radars (Abhilash et al 2007). The mesoscale models can be configured to run from global to cloud resolving scale for simulation of thunderstorms and cloud cluster properties.
They can also be used for a wide variety of applications such as, cloud-radiation interaction, cloudcloud interaction, transport of heat, moisture and momentum, pollution (Srinivas et al 2006), precipitation, interaction with surface fluxes, topographic effects (Das et al 2003; Das 2005), and, interaction with lower stratosphere, etc. Since the early 1990s several important changes have taken place in mesoscale modeling. First was the introduction of nonhydrostatic dynamics into mesoscale models (e.g., Dudhia 1993). The nonhydrostatic mesoscale models can be run at cloud resolving resolutions $(\sim 1 \mathrm{~km})$ without the restrictions of the hydrostatic assumption. This greatly increases the range of scientific problems to which the models can be applied. For example, at such resolutions, mesoscale models can explicitly simulate convection and its interaction with the larger

Keywords. Mesoscale; modeling; monsoon; forecast; errors; atmospheric sciences; meteorology. 
scale weather systems in a realistic way (Kuo and Wang 1996). However, the use of high-resolution mesoscale models for real-time NWP (list of acronyms are given in the appendix) requires a tremendous amount of computational resources. For example, to increase the grid resolution (both horizontally and vertically) of a model by a factor of two would require an increase in computational resources by a factor of 16 (Kuo 2003).

An open question usually asked is "Do higherresolution mesoscale models really produce better forecasts that are statistically significant?" To properly address such questions, careful statistical evaluation of a large number of forecasts is required (Davis and Carr 2000). Despite several mesoscale NWP efforts, careful statistical evaluation and verification of large numbers of real-time predictions have been rare. Recently, several studies have been devoted to such efforts (Colle et al 1999; Davis et al 1999). The results of these studies have produced a number of interesting conclusions:

- High resolution mesoscale models demonstrated considerable skill in predicting local circulations driven by topography and land-surface variations (Davis et al 1999). Such forecasts were often missed or not resolved by coarse resolution operational models.

- A noticeable improvement in the precipitation forecast in mountainous regions was found as the model horizontal resolution was increased from $36 \mathrm{~km}$ to $12 \mathrm{~km}$ (Colle et al 1999). However, subsequent improvement was not found for model resolution increasing from $12 \mathrm{~km}$ to $4 \mathrm{~km}$, except for heavy precipitation events. Case studies and sensitivity tests indicate that further improvements in microphysical schemes are required in order to predict precipitation more accurately.

- The skill of the model in mesoscale prediction is strongly affected by the quality of its large-scale forecasts (which are, in turn, strongly affected by the initial and boundary conditions provided by the larger scale models).

- Ensemble forecast experiments have indicated that the ensemble mean often possesses higher forecast skills than individual members of the ensemble (Grimit and Mass 2002).

At NCMRWF, mesoscale models such as MM5, ETA and RSM have been running on real-time basis since January 2002 for forecasting mesoscale systems. More recently, a new mesoscale model named WRF (weather research and forecasting) has been installed and is being tested at NCMRWF. The MM5 mesoscale model is run at NCMRWF at triple nested domains at 90, 30 and $10 \mathrm{~km}$ resolutions. The model is run on real time basis using the boundary conditions from the T80 global model of NCMRWF (Das 2002a, 2002b).
The ETA model is run over two domains (48 and $22 \mathrm{~km}$ resolutions) in a one way interactive mode (Rajagopal and Iyengar 2002, 2005). The RSM (Regional Spectral Model) has been running at NCMRWF at approximately $50 \mathrm{~km}$ resolution to downscale the forecasts of the T80 global model (Mohandas and Rajagopal 2005). The WRF model is presently run at $36 \mathrm{~km}$ horizontal resolution on an experimental basis.

While these models are run at NCMRWF at various resolutions for different applications, a systematic evaluation and comparison of performances between these models have not been done so far. Moreover, it also becomes expensive and decreases focus on the scientific development of a model if several models are run at a centre. The purpose of this work is to make a comprehensive study of all the mesoscale models being run at NCMRWF and, evaluate their performances for a complete monsoon season over the Indian region. In this paper we have evaluated the performance of all the four mesoscale models for Monsoon-2006 and computed forecast errors. Section 2 presents an overview of each model. Summary of all the four models including their dynamics, parameterization of physical processes, horizontal and vertical resolutions are given in table 1. The systematic errors of forecasts are discussed in section 3. The errors in rainfall forecasts are discussed in section 4 . In section 5 , evaluation of the forecasts of specific events such as lows, depressions and heavy rainfall episodes are carried out. Section 6 presents the skill scores of the forecasts. Finally, we present a summary of all the results in section 7 .

\section{Overview of mesoscale models run at NCMRWF}

In this section we present a brief description of the 4 meoscale models (MM5, ETA, RSM and WRF) run at NCMRWF as follows.

\subsection{The MM5 model}

The MM5 model is a non-hydrostatic, terrainfollowing sigma co-ordinate model developed at National Center for Atmospheric Research (NCAR), USA (Dudhia 2003; Grell et al 1994). The model (version 3.6) is run at triple nested domains (90, 30 and $10 \mathrm{~km}$ resolutions) over the Indian region on real time basis using the boundary conditions from the T80 global model of NCMRWF (Das 2002a, 2002b). There are 23 vertical sigma levels in the model. A summary of dynamics and different physical processes parameterized in the model is presented in table 1. Figure 1 illustrates the domains of the MM5 model. The middle domain 
Table 1. Summary of the models.

\begin{tabular}{|c|c|c|c|c|}
\hline Grid & MM5 & ETA & RSM & WRF \\
\hline $\begin{array}{l}\text { Horizontal } \\
\text { resolution }\end{array}$ & $90 / 30 / 10 \mathrm{~km}$ & $48 / 22 \mathrm{~km}$ & $50 \mathrm{~km}$ & $36 \mathrm{~km}$ \\
\hline Vertical levels & 23 & 38 & 18 & 31 \\
\hline Topography & USGS & Silhouette step & US Navy & USGS \\
\hline \multicolumn{5}{|l|}{ Dynamics } \\
\hline Time integration & Semi implicit & Semi implicit & Semi implicit & Semi implicit \\
\hline Time steps & $270 \mathrm{~s} / 90 \mathrm{~s} / 30 \mathrm{~s}$ & $\begin{array}{l}120 \mathrm{~s}(48 \mathrm{~km}) / \\
60 \mathrm{~s}(22 \mathrm{~km})\end{array}$ & $300 \mathrm{~s}$ & $180 \mathrm{~s}$ \\
\hline $\begin{array}{l}\text { Vertical } \\
\text { differencing }\end{array}$ & $\begin{array}{l}\text { Arakawa's energy } \\
\text { conserving scheme }\end{array}$ & $\begin{array}{l}\text { Euler backward } \\
\text { scheme }\end{array}$ & $\begin{array}{l}\text { Arakawa's energy } \\
\text { conserving scheme }\end{array}$ & $\begin{array}{l}\text { Arakawa's energy } \\
\text { conserving scheme }\end{array}$ \\
\hline Time filtering & Robert's method & & Asselin filter & Robert's method \\
\hline $\begin{array}{l}\text { Horizontal } \\
\text { diffusion }\end{array}$ & $\begin{array}{l}\text { 4th order for inner } \\
\text { domains. 2nd order } \\
\text { for the coarser } \\
\text { domains }\end{array}$ & $\begin{array}{l}\text { Modified Euler } \\
\text { backward with } \\
\text { Janic advection }\end{array}$ & 4th order & $\begin{array}{l}\text { 2nd order over } \\
\text { Quasi-pressure, } \\
\text { surface, scale } \\
\text { selective }\end{array}$ \\
\hline \multicolumn{5}{|l|}{ Physics } \\
\hline Convection & Grell & $\begin{array}{l}\text { Betts-Miller- } \\
\text { Janjic }\end{array}$ & $\begin{array}{c}\text { SAS scheme and } \\
\text { Tiedke scheme }\end{array}$ & Kain-Fritsch \\
\hline PBL & $\begin{array}{l}\mathrm{MRF} \\
\quad(\text { Non-local closure })\end{array}$ & $\begin{array}{l}\text { Mellor-Yamada } \\
\text { level } 2.5 \text { turbu- } \\
\text { lent exchange }\end{array}$ & Non local closure & YSU scheme \\
\hline $\begin{array}{l}\text { Cloud } \\
\text { microphysics }\end{array}$ & $\begin{array}{l}\text { Simple ice } \\
\text { (Dudhia) }\end{array}$ & $\begin{array}{l}\text { Explicit cloud } \\
\text { water/ice } \\
\text { prediction }\end{array}$ & $\begin{array}{l}\text { Slingo's scheme/ } \\
\text { grid scale rain }\end{array}$ & $\begin{array}{l}\text { WSM 3-class } \\
\text { simple ice }\end{array}$ \\
\hline Radiation & $\begin{array}{l}\text { Simple } \\
\text { cooling }\end{array}$ & GFDL & GFDL & $\begin{array}{l}\text { RRTM (LW) } \\
\text { Dudhia (SW) }\end{array}$ \\
\hline $\begin{array}{l}\text { Gravity wave } \\
\text { drag }\end{array}$ & No & No & Yes & No \\
\hline $\begin{array}{l}\text { Land surface } \\
\text { processes }\end{array}$ & Five layer soil model & $\mathrm{NOAH}$ & Pan and Mahrt & Thermal diffusion \\
\hline
\end{tabular}

of $30 \mathrm{~km}$ resolution covers all over India and neighbourhood, while the inner domain at $10 \mathrm{~km}$ resolution was initially placed over Jammu and Kashmir region to cater to the need of Mountain Meteorology program, which is a multi-institutional project involving SASE, NCMRWF, IMD, Army and IAF. In 2004, the inner domain at $10 \mathrm{~km}$ resolution was shifted over the central Himalayas and a fourth domain was configured over the West Bengal region to cater to the need of the national STORM (Severe Thunderstorm Observations and Regional Modelling) project.

\subsection{The ETA model}

The ETA model is a hydrostatic mesoscale weather forecast model with an accurate treatment of complex topography using Eta vertical co-ordinate and step-like mountains, which eliminates the errors in the computation of pressure gradient force over steeply sloped terrain present in sigma coordinate developed at the National Centers for Environmental Prediction (NCEP). The version used here follows that described by Black (1994) and Mesinger (1996). The model employs a semistaggered Arakawa E-grid in which wind points are adjacent to the mass points, configured in rotated spherical co-ordinates. The mesoscale ETA model is run operationally with a horizontal grid spacing of 48 and $22 \mathrm{~km}$ with 38 vertical levels, having layer depths that range from $20 \mathrm{~m}$ in the planetary boundary layer to $2 \mathrm{~km}$ at $50 \mathrm{mb}$ (Rajagopal and Iyengar 2003). The model top is at $25 \mathrm{hPa}$. Split explicit time differencing is used with a time step of 120 seconds. Spatial differencing is done with a conserving Arakawa type scheme. The model's step mountains are derived using the official United States Geological Survey (USGS) topographical data. It uses analysed SST from NCEP for its surface boundary conditions.

\subsection{The regional spectral model (RSM)}

The RSM used in the study is the latest version of NCEP RSM97 (Juang and Kanamitsu 1994; Juang 


\section{Domains of model integration}

(a) MM5

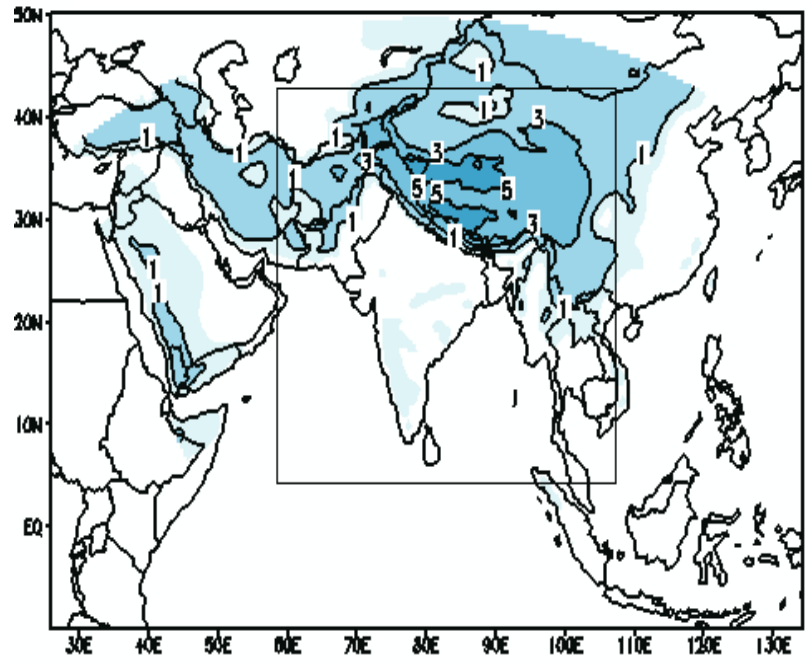

(b) Eta

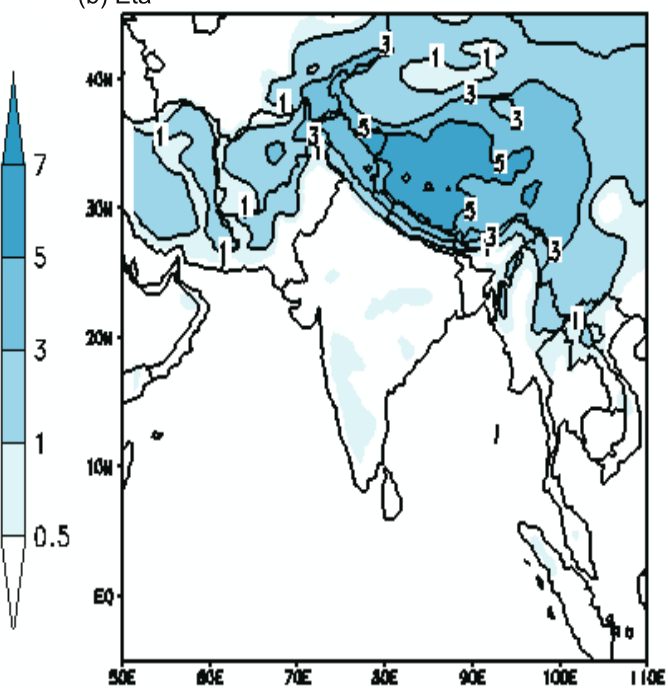

(c) RSM

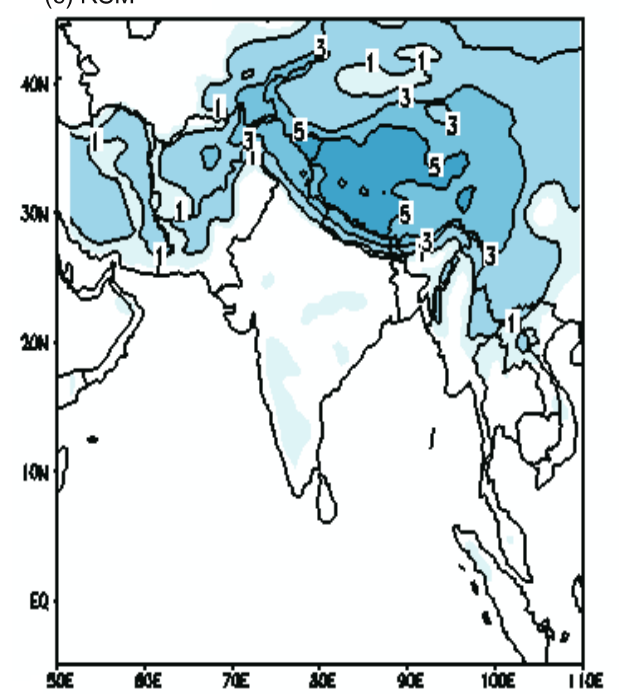

(d) WRF

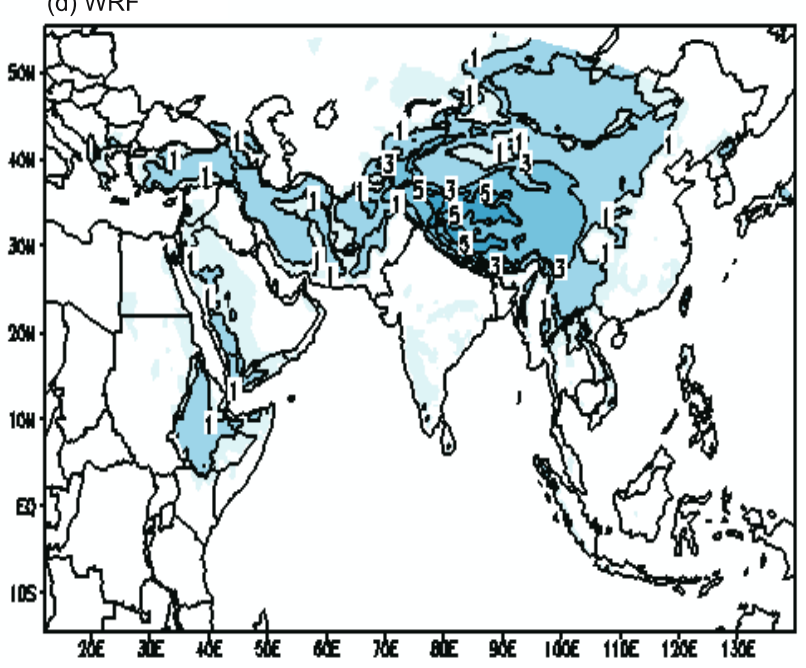

Figure 1. Domains of the MM5, ETA, RSM and WRF models.

et al 1997). It works on the philosophy of "Perturbation method". The model is one-way nested with the operational NCMRWF global spectral model, which has a horizontal resolution of T80 and a vertical resolution of 18 sigma levels. The nesting strategy used by RSM is domain and spectral nesting, which is characteristically different from the lateral boundary nesting strategy of conventional regional models. RSM allows global model forecast fields to be used over the entire domain and not just in the lateral boundary zone. The difference of the regional model fields from the base fields are called "perturbations" which are converted to wave space for the purpose of using semi-implicit time integration. The base fields are the timedependent global model forecasts. The nesting is done in such a way that the perturbation may be non-zero inside the regional domain but zero outside of it. Perturbation signifies all other features that could not be predicted by the global model but can be resolved over the regional domain by the regional model forecasts. The physics and the nonlinear dynamics are computed in grid space only with full regional model fields. The basis functions for spectral conversion are double sine cosine series with 72 waves along zonal and 70 waves along the meridional direction. The domain is approximately $52^{\circ} \mathrm{E}-109^{\circ} \mathrm{E}$ and $6^{\circ} \mathrm{S}-45^{\circ} \mathrm{N}$ and covers the whole of India and nearby oceanic regions (Mohandas and Rajagopal 2005). The RSM has horizontal resolution of $50 \mathrm{~km}$ and 18 levels in the vertical. The time step of the model is 5 minutes and the nesting period is 6 hours. It uses analysed SST from NCEP for its surface boundary conditions. 
RSM predicts the relatively smaller perturbations superimposed over the previously predicted large-scale components by the global model, which was run prior to it. Hence the errors introduced in the perturbation due to the lateral boundary will remain small which enables a longer period time integration compared to the conventional grid point regional models. The lateral boundary is relaxed towards the global model values using Tatsumi's boundary relaxation scheme. It is more logical for the perturbation values to approach zero along the boundary. Table 1 summarizes the main features of the model.

\subsection{The WRF model}

The Weather Research and Forecasting (WRF) Model is a next-generation mesocale numerical weather prediction system designed to serve both operational forecasting and atmospheric research needs. It features multiple dynamical cores, a 3-dimensional variational (3DVAR) data assimilation system, and a software architecture allowing for computational parallelism and system extensibility. WRF is suitable for a broad spectrum of applications across scales ranging from meters to thousands of kilometers. Applications of WRF include research and operational numerical weather prediction (NWP), data assimilation and parameterized-physics research, downscaling climate simulations, driving air quality models, atmosphere-ocean coupling, and idealized simulations (i.e., boundary-layer eddies, convection, baroclinic waves). There are two dynamic solvers in the WRF system: the Advanced Research WRF (ARW) solver (originally referred to as the Eulerian mass or "em") developed primarily at NCAR, and the NMM (Nonhydrostatic Mesoscale Model) solver developed at NCEP. The ARW system consists of the ARW dynamics solver with other components of the WRF system needed to produce a simulation. At NCMRWF, the WRFARW system is used. Details of the dynamics and physics options used at NCMRWF are listed in table 1 . In this study we have used WRF-ARW version 2.1. The model is run on a single domain covering the Indian region at $36 \mathrm{~km}$ horizontal resolution and 31 vertical levels.

\section{Systematic errors}

Systematic errors affect all ranges of prediction, and are a substantial part of the total forecast errors. A large part of the forecasting deficiencies is connected with the imperfect assimilation of available data in the numerical prediction process.
Forecast errors are commonly separated into a systematic component (defined as the time mean of the forecast errors for a certain forecast interval) and a non-systematic or random part. For extended forecast ranges, the mean error is almost constant and equal to the differences between the model's climate and the observed climate, known as climate drift. The spatial distribution of systematic errors in the medium range has large scale features similar to climate drift, indicating that those error components are mainly associated with deficiencies in model formulation. At present the systematic error, defined as the time mean error and representing the steady drift more or less independent of flow regime, is only a small part of the total error (Ferranti et al 2000). The seasonal forecast drift, in fact is only about $5 \%$ of the total forecast error at day 10 (Mureau 1990). It is however, important to realize that the size and the structure of the systematic errors depend on the averaging time periods and for short averaging periods (like 10-20 days) the errors become more and more flow dependent. Mureau (1990) showed that the error averaged over a 10-20 days period is about 3 times larger than its seasonal mean. Model errors are dependent on flow regimes and manifest themselves on various time-scales (Palmer 1988).

\subsection{Systematic errors of wind and geopotential fields}

Figure 2 illustrates the monthly mean systematic errors of day-3 forecasts of winds and geopotential fields at $850 \mathrm{hPa}$. We have not shown the diagrams for day- 1 and day-2 for brevity. The shading indicates errors in the zonal winds in $\mathrm{m} \mathrm{s}^{-1}$. The contours indicate systematic errors of geopotential fields. Results indicate that the models tend to weaken the Cross-Equatorial Flow (CEF) by producing an easterly bias over the Arabian Sea. Maximum bias (up to $10 \mathrm{~m} \mathrm{~s}^{-1}$ ) is seen in MM5 and WRF models. All models produce strong westerly bias up to $10 \mathrm{~m} \mathrm{~s}^{-1}$ over the north-eastern region. The ETA model also produces strong westerly bias over south Indian peninsular India. It has a tendency to produce cyclonic torque over Orissa and adjoining Andhra Pradesh, while the RSM has a tendency to produce the cyclonic vorticity across the southern peninsular in the month of September (figure not shown for brevity). Results show that all the four models produce errors ranging from 0-10 geopotential meters (gpm) over most of the Indian region. The magnitude of the systematic errors is larger (up to about $30 \mathrm{gpm}$ ) over Afghanistan and the Arabian region in the MM5 and WRF models.

Figure 3 presents the monthly mean systematic errors of day- 3 forecasts of winds and geopotentials 
(a) MM5
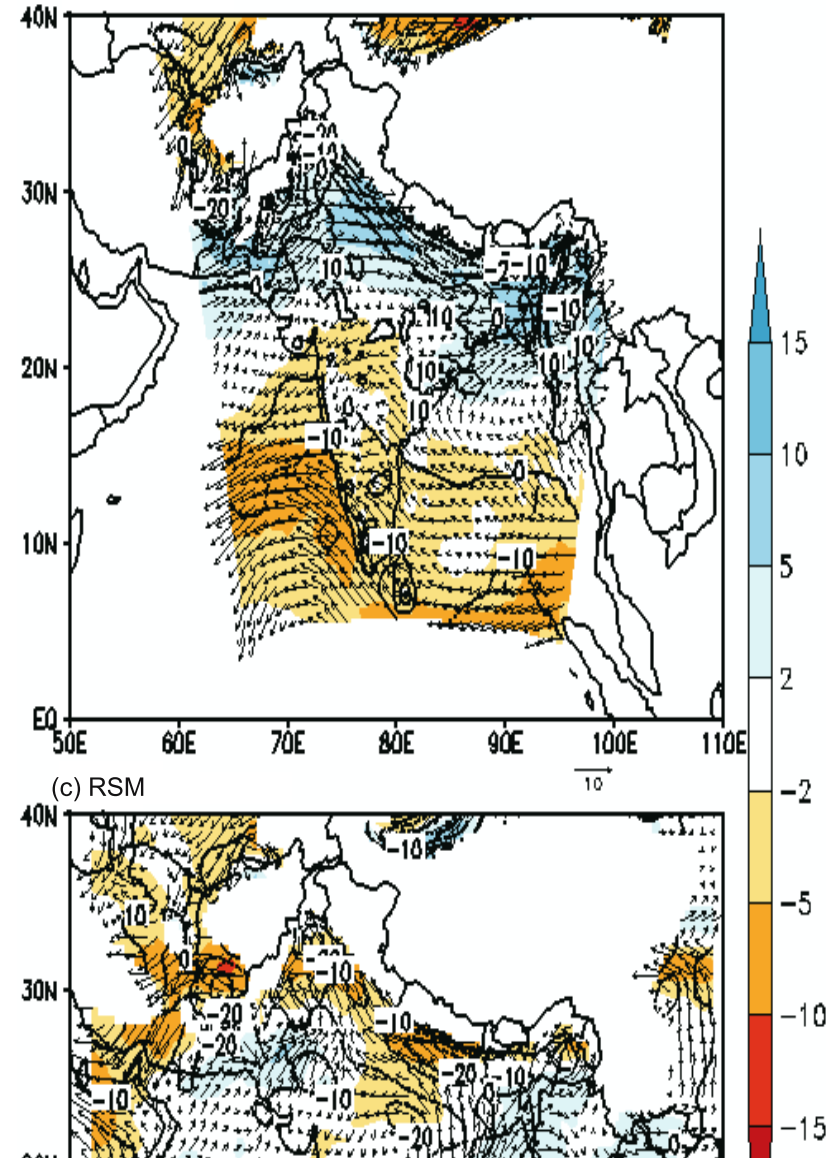

$20 \mathrm{~N}$

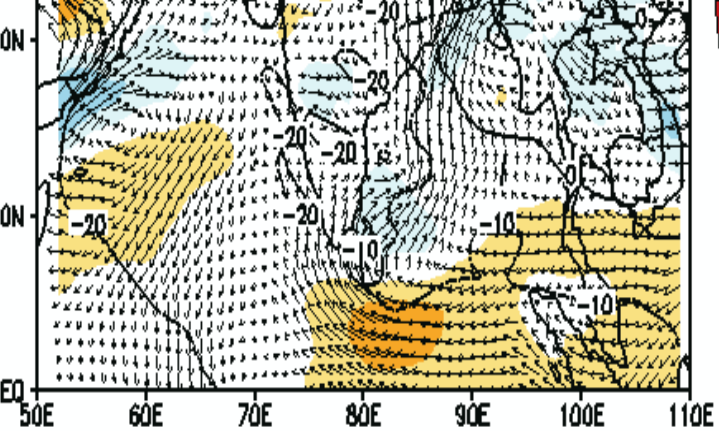

(b) Eta

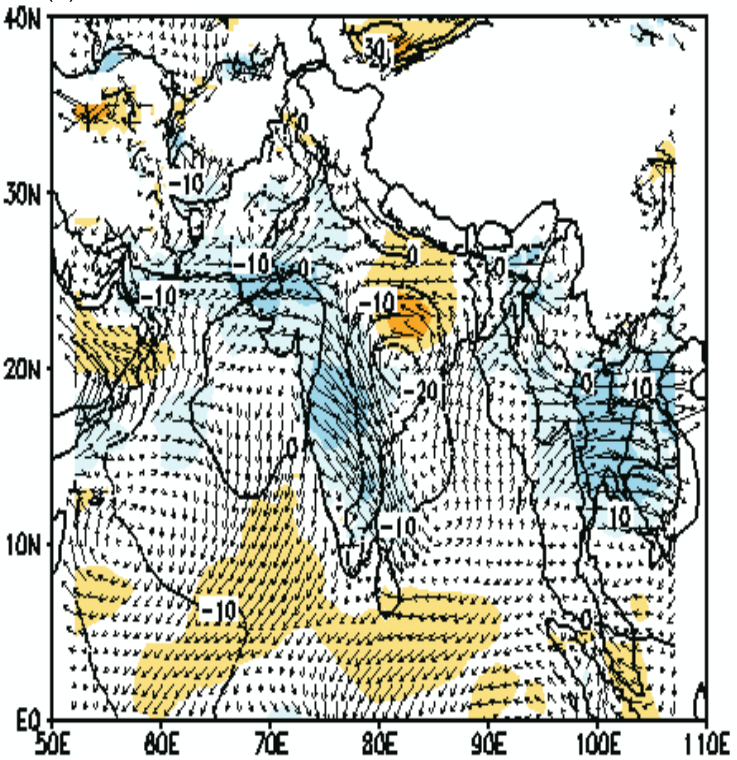

(d) WRF

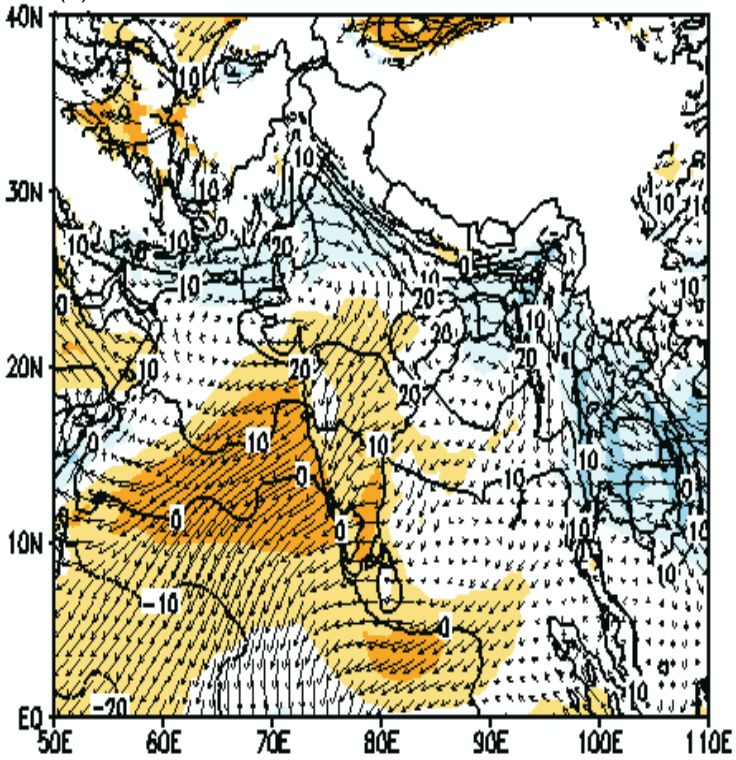

Figure 2. Systematic errors of $850 \mathrm{hPa}$ winds and geopotentials (contours) for day-3 forecasts of July 2006 for (a) MM5, (b) ETA, (c) RSM, and (d) WRF. Shading indicates errors in zonal wind $\left(\mathrm{m} \mathrm{s}^{-1}\right)$. Thick black contours indicate errors in geopotential fields.

at $200 \mathrm{hPa}$. At the upper level, westerly bias is seen between 15 and $20^{\circ} \mathrm{N}$ across the Arabian Sea, central India and the Bay of Bengal in all the models except WRF. Strong easterly bias is seen in both ETA and WRF models over south-east Indian Ocean across the Malay peninsular. The MM5 model produces stronger easterlies over the Himalayas at $200 \mathrm{hPa}$. The RSM produces relatively least systematic errors at $200 \mathrm{hPa}$ compared to other models. The magnitude of the systematic errors of geopotential field is larger (up to about 40 gpm in MM5 and WRF models).
Study of the systematic errors of the global T80 model, indicates that the model produces an anomalous cyclonic circulation over eastern and central parts of India and anticyclonic circulation over the southern Bay of Bengal and adjoining peninsula. The circulation pattern in the global model tends to weaken the monsoon flow at $850 \mathrm{hPa}$ and the subtropical westerly jet at $200 \mathrm{hPa}$. As the mesoscale models are run by using the initial and boundary conditions from the global model, it is possible that some of these features may be related to the boundary conditions of the T80 model, but 
DAY-3 FCST: Syserr Winds ( $\mathrm{m} / \mathrm{s})$ at $200 \mathrm{hPo}$ for july 06

(a) MM5
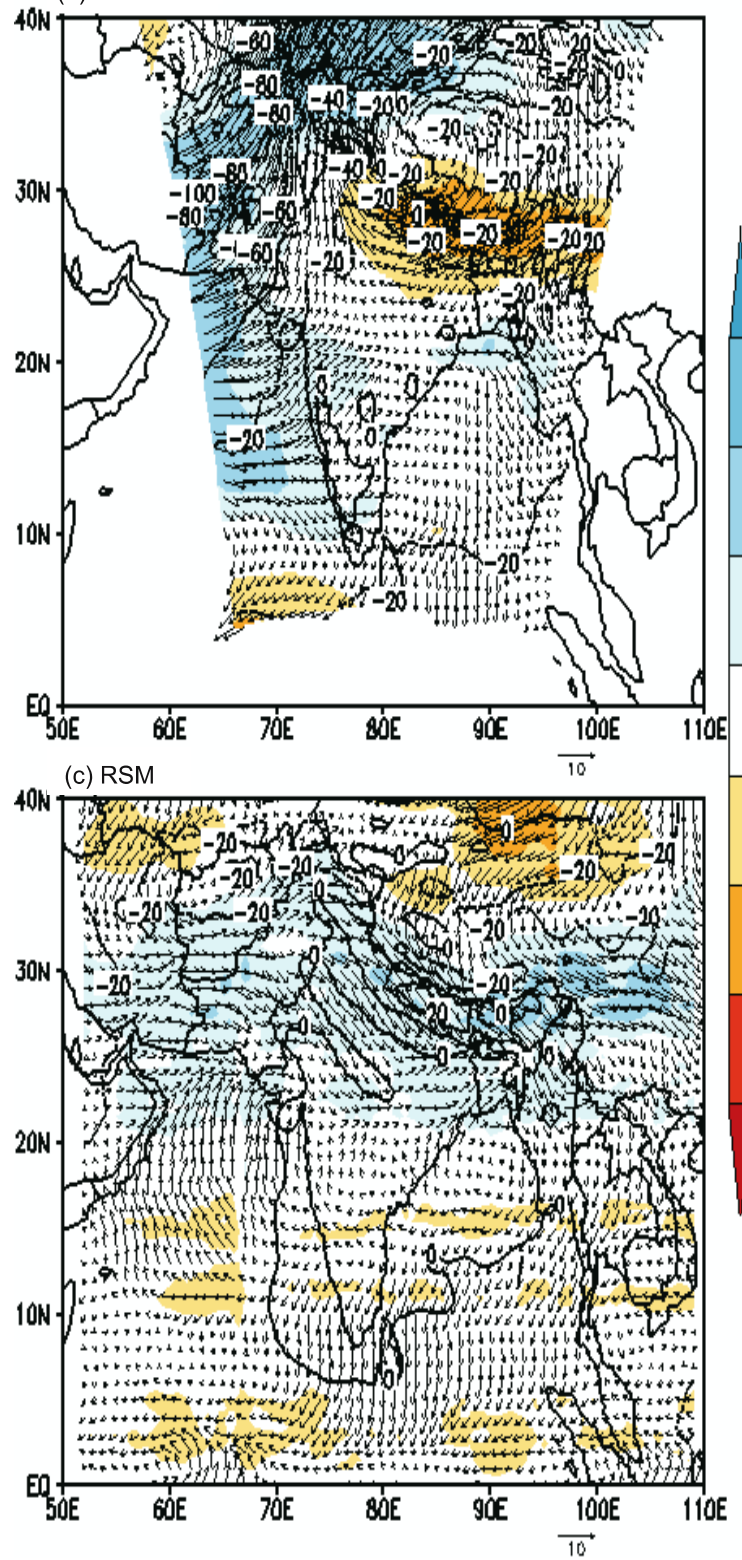

(b) Eta

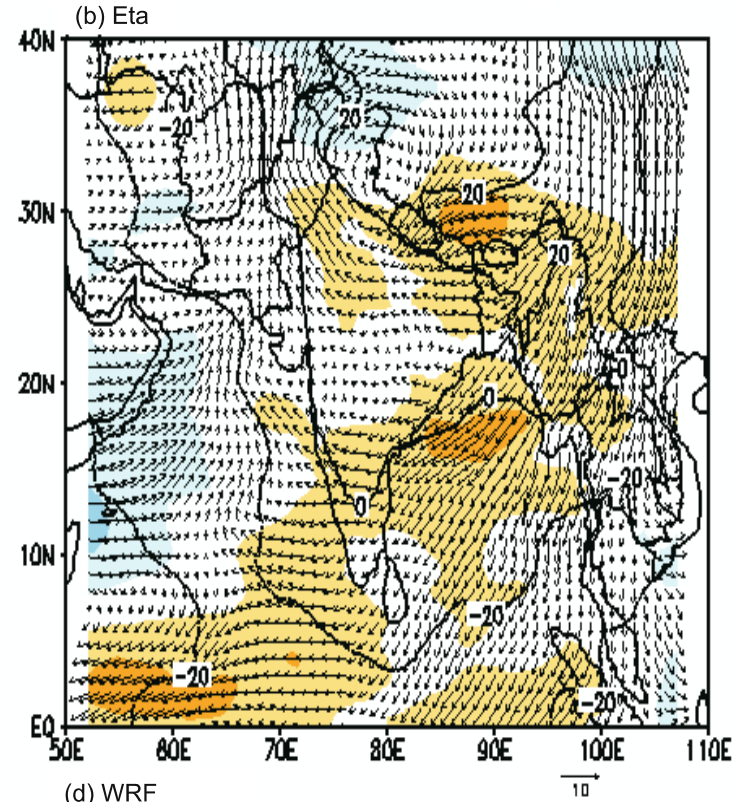

$-2$

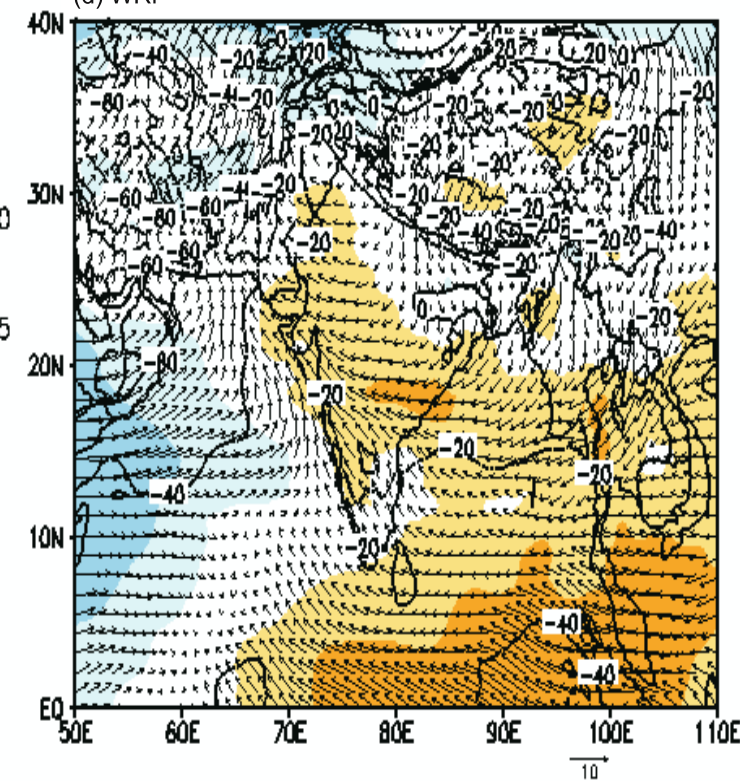

Figure 3. As in figure 2 but for $200 \mathrm{hPa}$ of day-3.

most of them may be due to the inherent features of the mesoscale models.

\subsection{Systematic errors of temperature}

Figure 4 illustrates the monthly mean systematic errors of day-3 forecasts of temperature at $850 \mathrm{hPa}$ shown by thick black contours. The shadings shown in the diagrams indicate systematic errors in the specific humidity (discussed in section 3.3). The diagrams indicate that both MM5 and WRF produce cold bias (up to $-5.5^{\circ} \mathrm{C}$ ) at $850 \mathrm{hPa}$ over most parts of central and north India. The cold bias is less in the WRF compared to MM5. On the other hand both ETA and RSM produce warm bias (up to $3^{\circ} \mathrm{C}$ ) over most parts of India. The warm bias increases up to $4^{\circ} \mathrm{C}$ in the ETA model from July to August. The bias is less in the RSM compared to ETA.

Figure 5 illustrates the monthly mean systematic errors of day- 3 forecasts of temperature at $200 \mathrm{hPa}$. Warm regions are shaded in the diagrams. The figures indicate that the MM5, ETA and RSM produce warm bias (up to $1.5^{\circ} \mathrm{C}$ ) over the southern peninsular and adjoining sea and cold bias at the remaining areas. The WRF produces cold bias (up to $-1.5^{\circ} \mathrm{C}$ ) over most parts of India. The RSM also produces warm bias over east UP and Bihar. The 
DAY-3 FCST: Syserr Temp \& Sp. Hum at 850 hPo for july 06
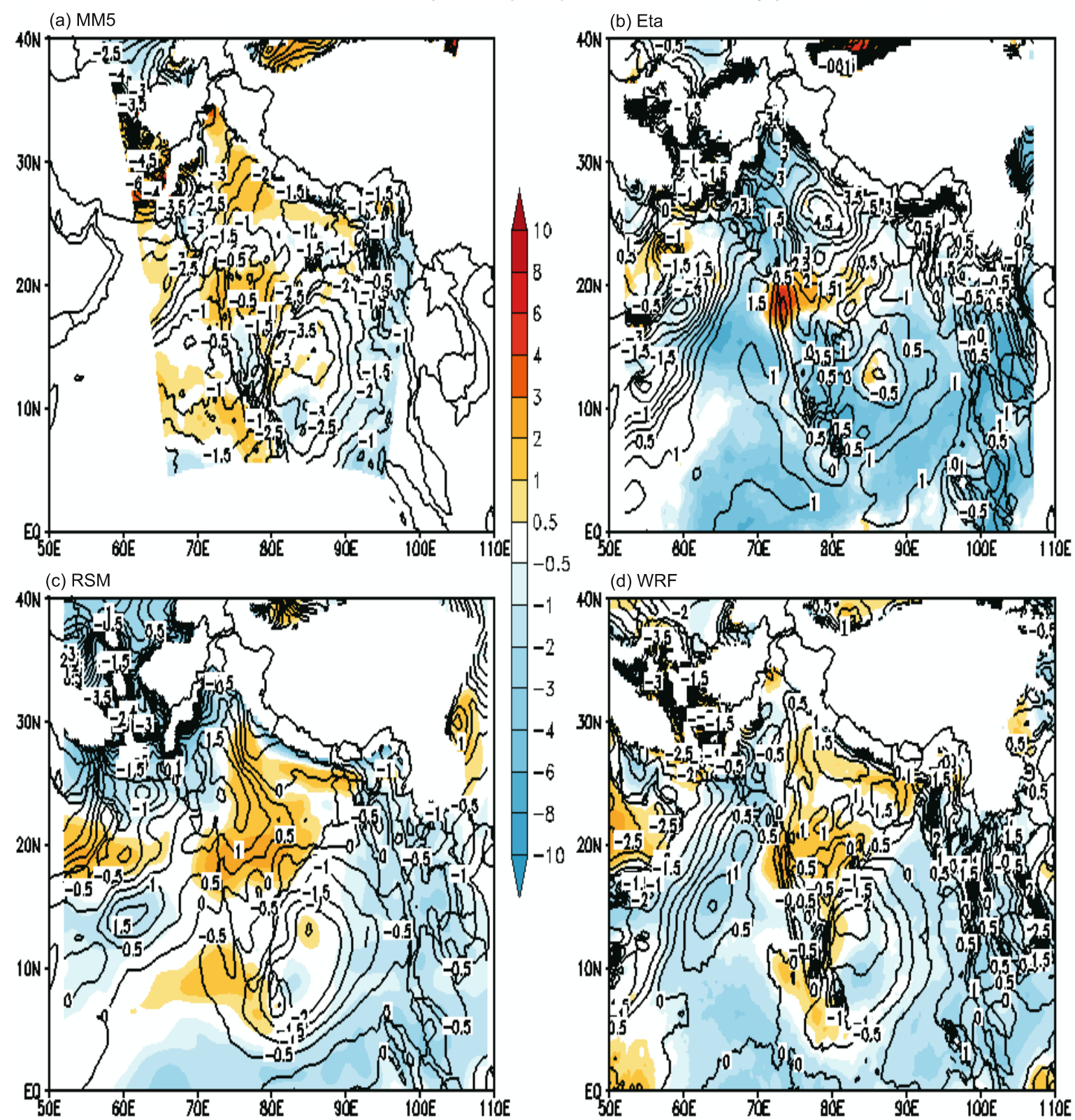

(d) WRF

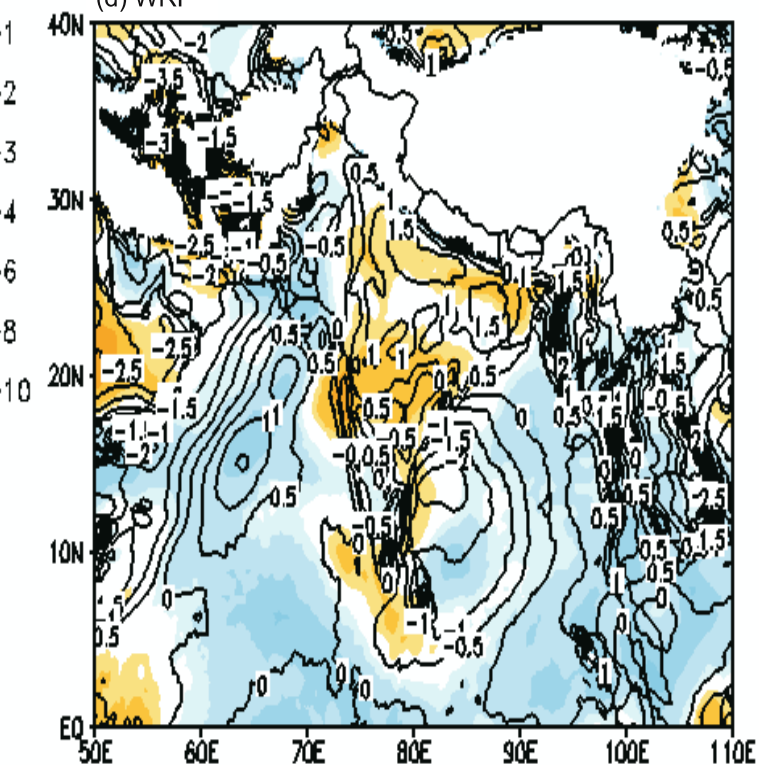

Figure 4. Systematic errors of $850 \mathrm{hPa}$ temperature $(\mathrm{K})$ and specific humidity $\left(\mathrm{g} \mathrm{kg}^{-1}\right)$ for day-3 forecasts of July 2006 for (a) MM5, (b) ETA, (c) RSM, and (d) WRF. Thick black contours are for temperature and the shadings are for the specific humidity.

warm bias is less in the MM5 model. On the other hand, it increases in the ETA and RSM models in July-September. The WRF model remains cold in all the three months.

\subsection{Systematic errors of specific humidity}

The monthly mean systematic errors of day-3 forecasts of specific humidity at $850 \mathrm{hPa}$ are shown by the shaded region in figure 4 . The diagrams indicate that the MM5 and WRF models produce moist bias (up to about $2-3 \mathrm{~g} \mathrm{~kg}^{-1}$ ) particularly over north India, while the ETA model produces dry bias (up to about $3-4 \mathrm{~g} \mathrm{~kg}^{-1}$ ). The RSM produces least errors compared to the three models. The errors are relatively less over the Indian region in MM5 and WRF models during July-September, whereas it increased slightly in ETA and RSM. Both these models produced moist bias on the west coast off Mumbai during July and August. The MM5 model produced least errors in the day-3 forecasts of specific humidity compared to the other three models, whereas the RSM produced less error only in June compared to the other models. 

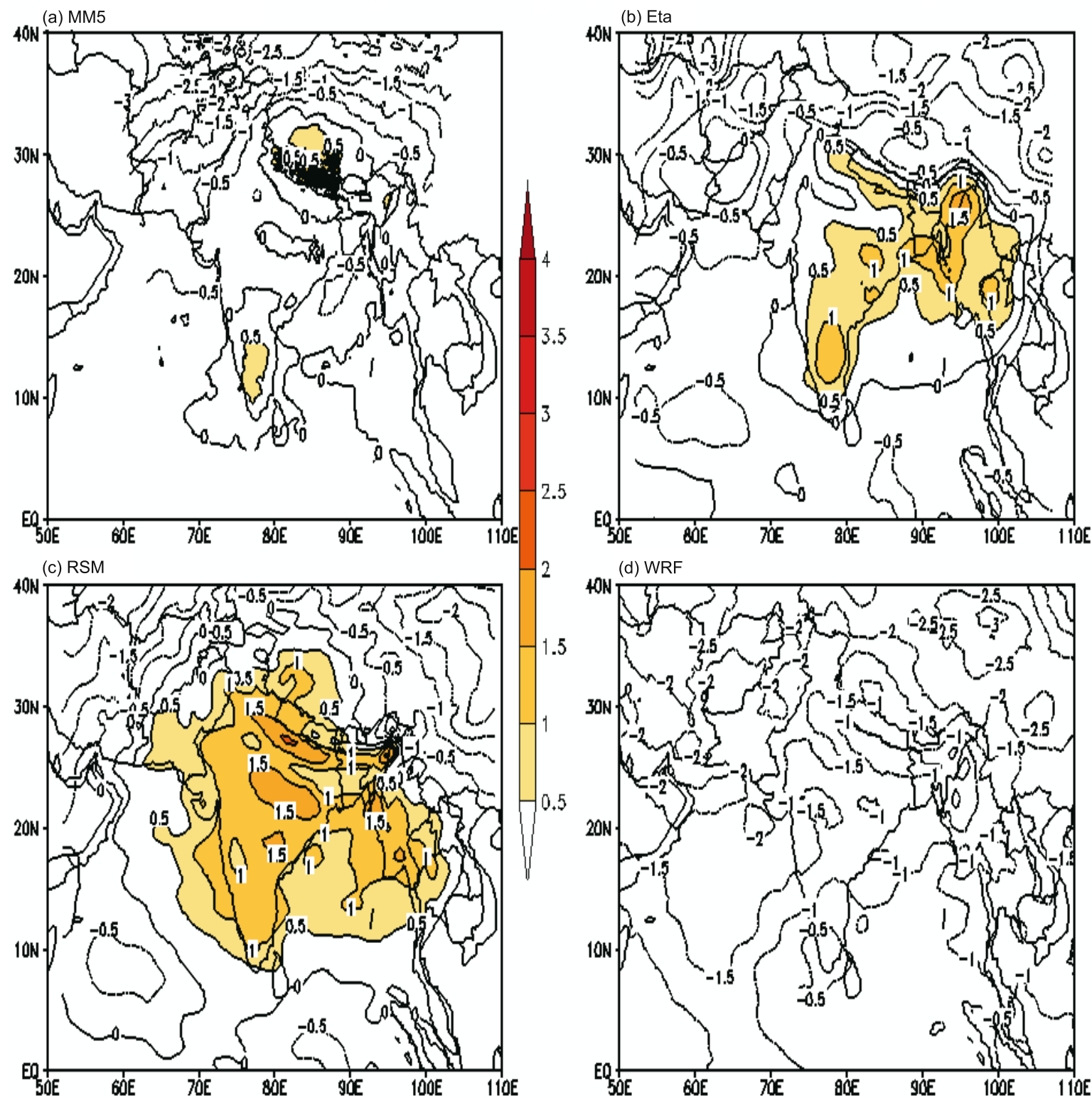

Figure 5. Systematic errors of $200 \mathrm{hPa}$ temperature (K) for day-3.

\section{Rainfall}

The mean monthly observed rainfall for the month of July is shown in figure 6. The observed distribution of rainfall was obtained by merging daily values of rain gauge and TRMM observations at $25 \mathrm{~km}$ resolutions following Mitra et al (2003). The observed distribution of rainfall indicates the typical maxima (1-2 $\mathrm{cm}$ day $\left.^{-1}\right)$ over the west coast of India during June. A secondary maximum is seen over the Bay of Bengal off Arakan coast and the north-eastern states. The rainfall values increased in July with the progress of the monsoon. The maximum values $\left(2-4 \mathrm{~cm} \mathrm{day}^{-1}\right)$ are seen off the west coast and the Arakan coast in the north Bay of Bengal. The rainfall values are relatively less in August and reduced further in the month of September (Das et al 2007).

Figure 7 presents the mean day-3 forecast of rainfall $\left(\mathrm{cm} \mathrm{day}^{-1}\right)$ obtained from the four models. While none of the models are able to produce rainfall distributions close to the observations, typical characteristics like the west coast maximum is produced better by the ETA and RSM. The MM5 and WRF are able to produce the maximum over the west coast, but its location is slightly south of the observed location. The extended belt of rainfall observed over the Arabian Sea and the rainfall maximum off the Arakan coast are produced fairly well by all the models. However, the 


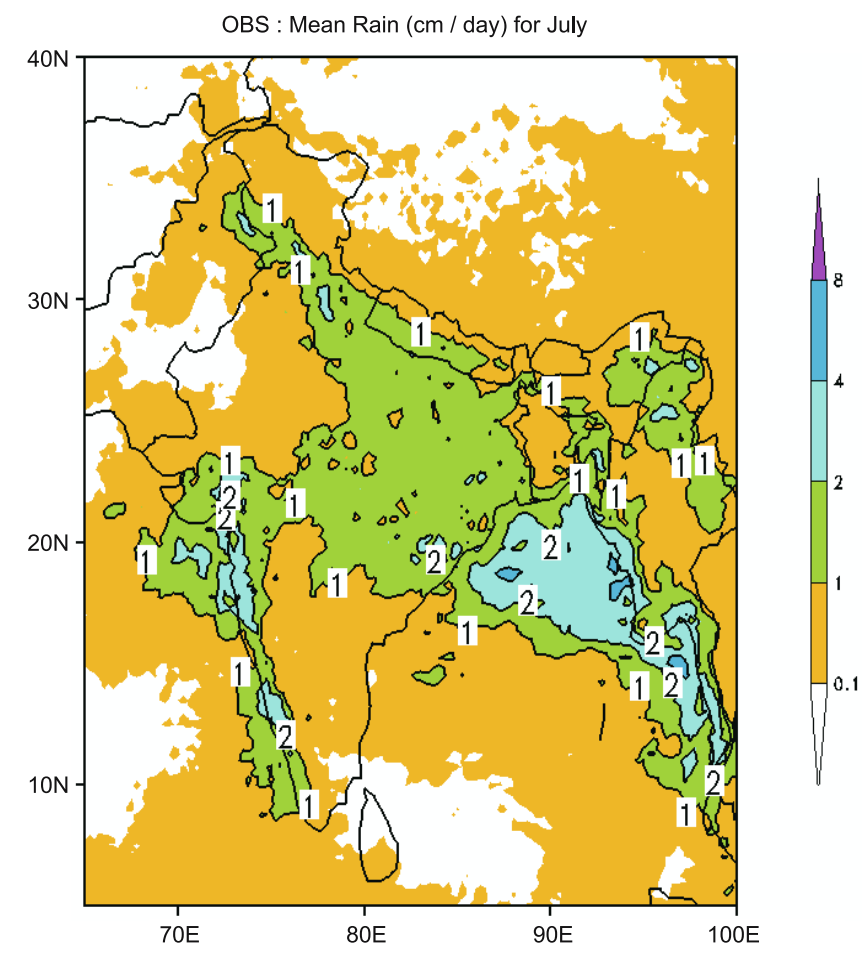

Figure 6. Analyzed (rain gauge + TRMM) rainfall averaged for July 2006.

rainfall values are overestimated by the ETA model (4-8 $\mathrm{cm}$ day $^{-1}$ against $2-4 \mathrm{~cm}$ day $^{-1}$ as per observations). Both ETA and RSM overestimated the magnitude of rainfall over the Arakan coast as compared to observations. The MM5 model produced relatively better distribution of rainfall over the Indo-Gangetic plains, where the values are underestimated by the ETA and WRF models and overestimated by the RSM.

\section{Lows and depressions}

During monsoon-2006 sixteen systems (1 severe cyclonic storm, 8 depressions/deep depressions and 7 low pressure/well marked low pressure areas) formed over the Indian region. Most of the systems formed over the Bay of Bengal except one severe cyclonic storm (Mukda) that formed over the Arabian Sea during 21-24 September. The systems that formed in the Bay of Bengal moved mostly in west-northwesterly direction across the land and caused heavy precipitation over Orissa, Madhya Pradesh, Maharastra, Gujarat and west Rajasthan. Among the eight depressions, one formed during 1-6 July, one deep depression during 1-14 August, and three depressions during 11-13, 16-23 and 28-31 August and 3 depressions during 3-7, 21-26, and 28-30 September. The four depressions that formed in the month of August was a record for the month since 1919 as per IMD. In this section we have presented a detailed discussion of the deep depression of 1-14 August that had long track originating in the Bay of Bengal and reaching almost up to Rajasthan/Gujarat. We have presented the analyzed tracks and the predicted (day-1 and day-3) tracks obtained from the 4 models. Locations of the systems have been determined based on the centres of the cyclonic circulations at $850 \mathrm{hPa}$. Finally, the RMSE of the predicted tracks by the 4 models are also presented.

\subsection{Deep depression of 1-14 August}

A low pressure area formed over the north Bay off the coast of Orissa and West Bengal on 1 August and intensified into a depression on 2 August at $3 \mathrm{UTC}$ near $20.5^{\circ} \mathrm{N}, 87.5^{\circ} \mathrm{E}$. It intensified into a deep depression at 12 UTC of the same day. It crossed the south Orissa coast between Puri and Gopalpur at 03 UTC on 3 August and moved west northwestward. It weakened into a depression on 5 August and continued its movement in the same direction across Madhya Pradesh and east Rajasthan and became less marked on 14 August. It produced heavy rainfall over central parts of the country and west central peninsular along its track especially due to its long stay.

Figure 8 illustrates the analyzed track obtained from UKMO models and the day- 1 and day-3 forecasts by the 4 mesoscale models. The UKMO analysis is generally considered better than the T80, because of higher spatial resolution and radiance data assimilation from satellites (Bohra et al 2006). Therefore, in the present study the analyzed tracks (ANA) from UKMO have been used for comparison with the forecast tracks from the mesoscale models. The analyzed track shows looping of the system after it reached near east Rajasthan. The figure indicates that while there are differences between the analyzed and predicted tracks, all the models are able to forecast correct direction of movement in the day- 1 forecast at least till the system started looping. None of the models could produce proper track in their day-3 forecasts, particularly when the system started looping. MM5 produced the largest deviation, while the ETA produced better track in the day- 1 forecast. The models also tried to fill up the system in day-3 forecasts on some of the days and reproduced the system in the prediction based on the next day. This also highlights the importance of the initial and boundary conditions.

\subsection{RMSE of the tracks}

Table 2 presents the root mean square errors of the day- 1 and day- 3 forecasts of tracks based 
(a) MM5

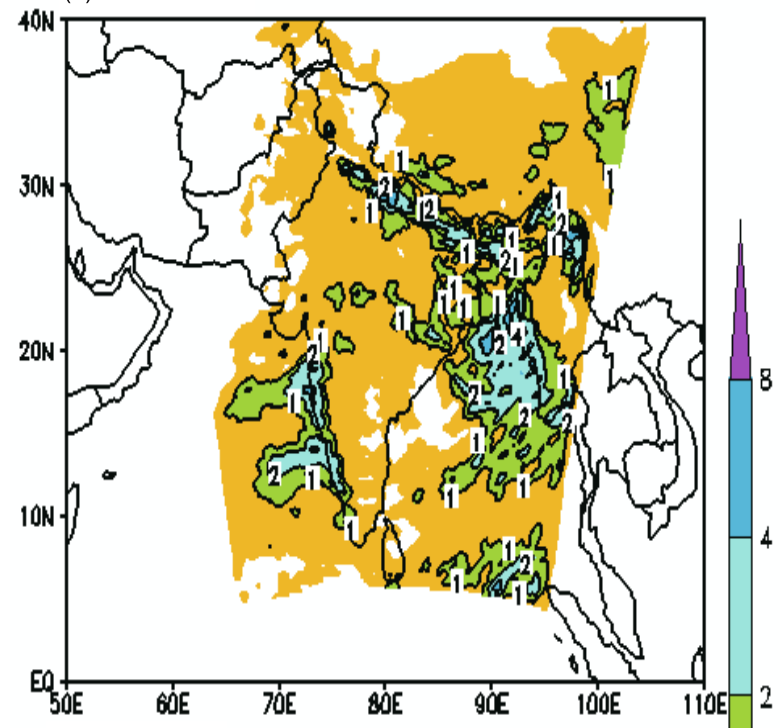

(c) RSM

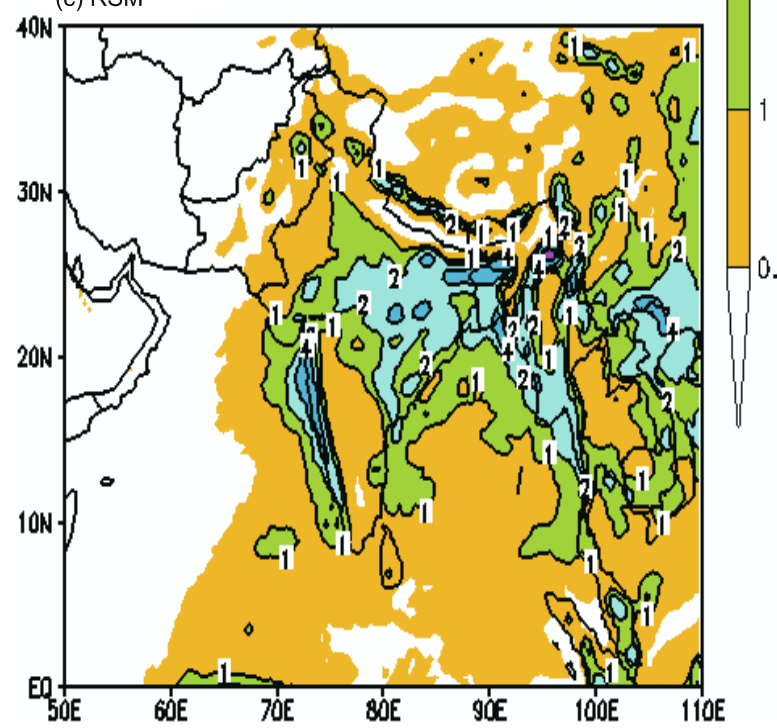

(b) Eta

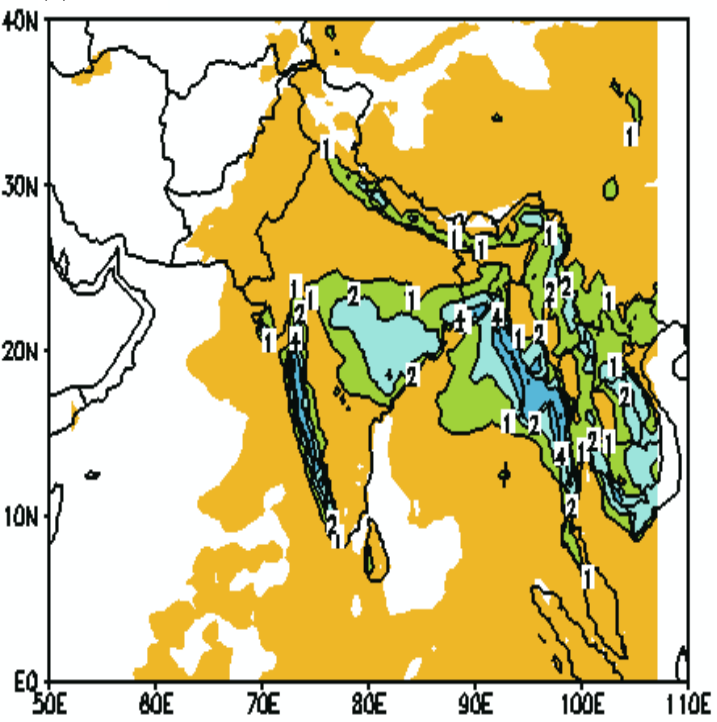

(d) WRF

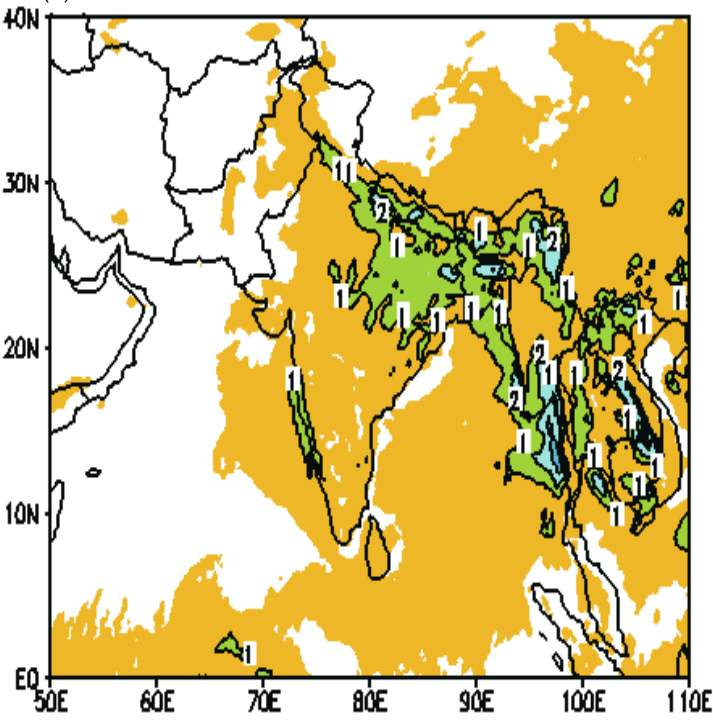

Figure 7. Mean day-3 forecast of rainfall $\left(\mathrm{cm} \mathrm{day}^{-1}\right)$ for July 2006 obtained from (a) MM5, (b) ETA, (c) RSM and (d) WRF.

on the three depressions that had longest path originating in the Bay of Bengal and reaching almost up to Rajasthan/Gujarat (i.e., 1-14 August, 16-23 August and 3-7 September). The track errors of each model have been computed relative to their own analyses. Comparisons of the RMSE reveal that while the RSM produced least errors $(193.138 \mathrm{~km})$ in the day-1 forecasts of the tracks, the ETA model produced least errors $(371.546 \mathrm{~km})$ in the day-3 forecasts. Experience shows that the track errors are less in cases of cyclonic storms than compared to lows and depressions, because the circulation fields are not well defined in the forecast fields when a system is weak.

\section{Forecast skill scores}

There are several standard statistical scores to examine and quantify the skills of forecasts such as, the Root mean Square Error (RMSE), Bias, Threat Score, Brier score, Heidke skill score, HanssenKuipers skill statistics, true skill score statistics (Doswell et al 1990; McBride and Ebert 2000). Wilks (1995) has described different methods of forecast verification. In order to examine the forecast skill scores of the four mesoscale models in the present study, we have simply computed the RMSE of zonal wind $(u)$, meridional wind $(v)$ and geopotentials $(z)$ at 850 and $200 \mathrm{hPa}$ and specific humidity $(q)$ at $850 \mathrm{hPa}$ over the Indian region 
Track of the System during 1st - 14th August,2006 Day 1 Forecast

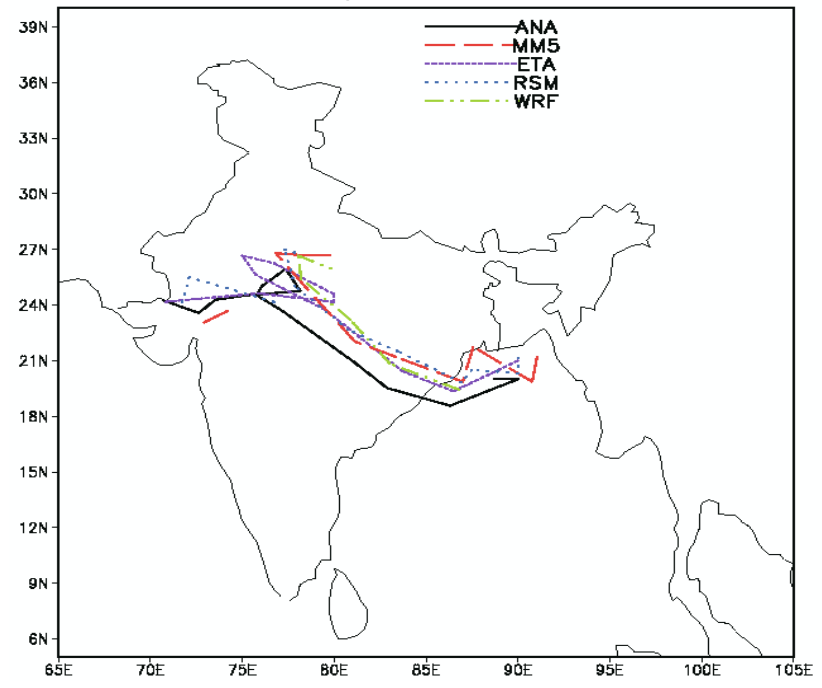
Track of the System during 1 st -14 th August,2006
Day 3 Forecast

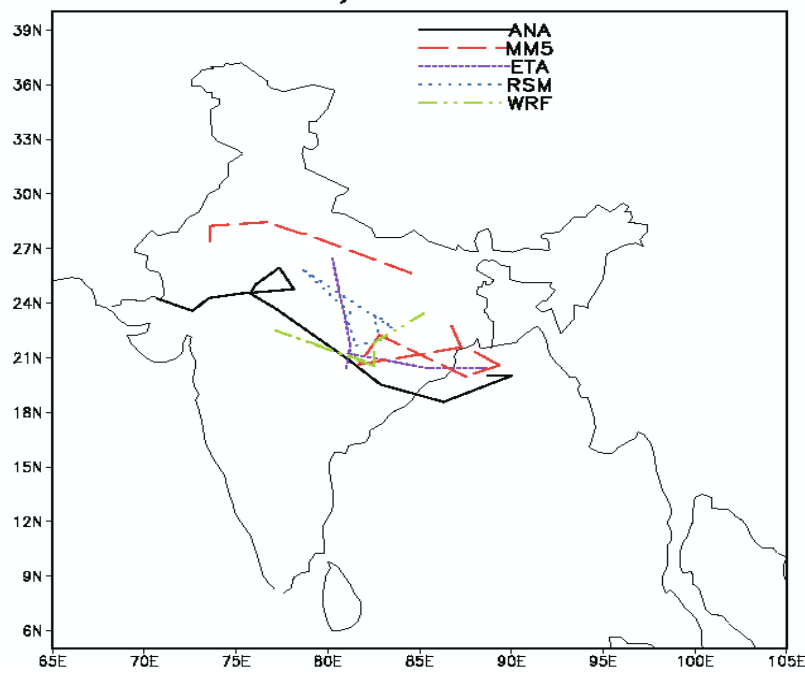

Figure 8. Tracks of the monsoon low during 1-14 August 2006 obtained from analysis (UKMO), and forecasts from MM5, ETA, RSM and WRF models for (a) day-1 and (b) day-3 forecasts based on different initial conditions of 29 July to 13 August.

Table 2. RMSE of track of the lows and depressions, in $\mathrm{km}$.

\begin{tabular}{|c|c|c|c|c|}
\hline & MM5 & ETA & RSM & WRF \\
\hline \multicolumn{5}{|c|}{ System from 1 August - 14 August, 2006} \\
\hline Day1 & 209.672 & 221.524 & 189.72 & 246.141 \\
\hline Day3 & 426.384 & 309.46 & 422.208 & 495.642 \\
\hline \multicolumn{5}{|c|}{ System from 16 August - 23 August, 2006} \\
\hline Day1 & 222.274 & 241.125 & 235.616 & 291.19 \\
\hline Day3 & 532.521 & 449.843 & 595.647 & 482.548 \\
\hline \multicolumn{5}{|c|}{ System from 3 September - 7 September, 2006} \\
\hline Day1 & 214.229 & 119.102 & 122.253 & 188.38 \\
\hline Day3 & 571.508 & 370.344 & 399.393 & 694.154 \\
\hline \multicolumn{5}{|c|}{ Composite } \\
\hline Day1 & 214.365 & 209.414 & 193.138 & 248.747 \\
\hline Day3 & 478.861 & 371.546 & 482.33 & 539.244 \\
\hline
\end{tabular}

$\left(5-40^{\circ} \mathrm{N}, 65-100^{\circ} \mathrm{E}\right)$. The RMSE values have been computed with reference to the respective analyses of the models. The skill scores of the rainfall forecasts have been examined by computing the threat scores for different threshold values. We have also computed the All India area averaged rainfall and compared with the observations.

\subsection{RMSE of zonal and meridional wind}

Figure 9 illustrates the RMSE of day-1, day-2 and day- 3 forecasts of zonal and meridional wind $\left(\mathrm{m} \mathrm{s}^{-1}\right)$ at 850 and $200 \mathrm{hPa}$ for the month of July. Results show that the MM5 performed better in July in all the 24, 48 and 72 hours forecasts. It produced least RMSE in day-1 forecasts of August and September also (figure not shown), while ETA was better in the day-3 forecasts of these months. At upper level (200 hPa), the MM5 and WRF generally produced less RMSE.

The RMSE of meridional wind indicates that RSM produced highest RMSE in all the 4 months at lower and upper levels. Both MM5 and WRF produced best day-3 forecasts in July.

\subsection{RMSE of geopotential height and specific humidity}

Figure 10 illustrates the RMSE of day-1, day-2 and day-3 forecasts of geopotential heights (gpm) at 850 and $200 \mathrm{hPa}$. Results indicate that RSM produced highest RMSE of geopotential fields in all 

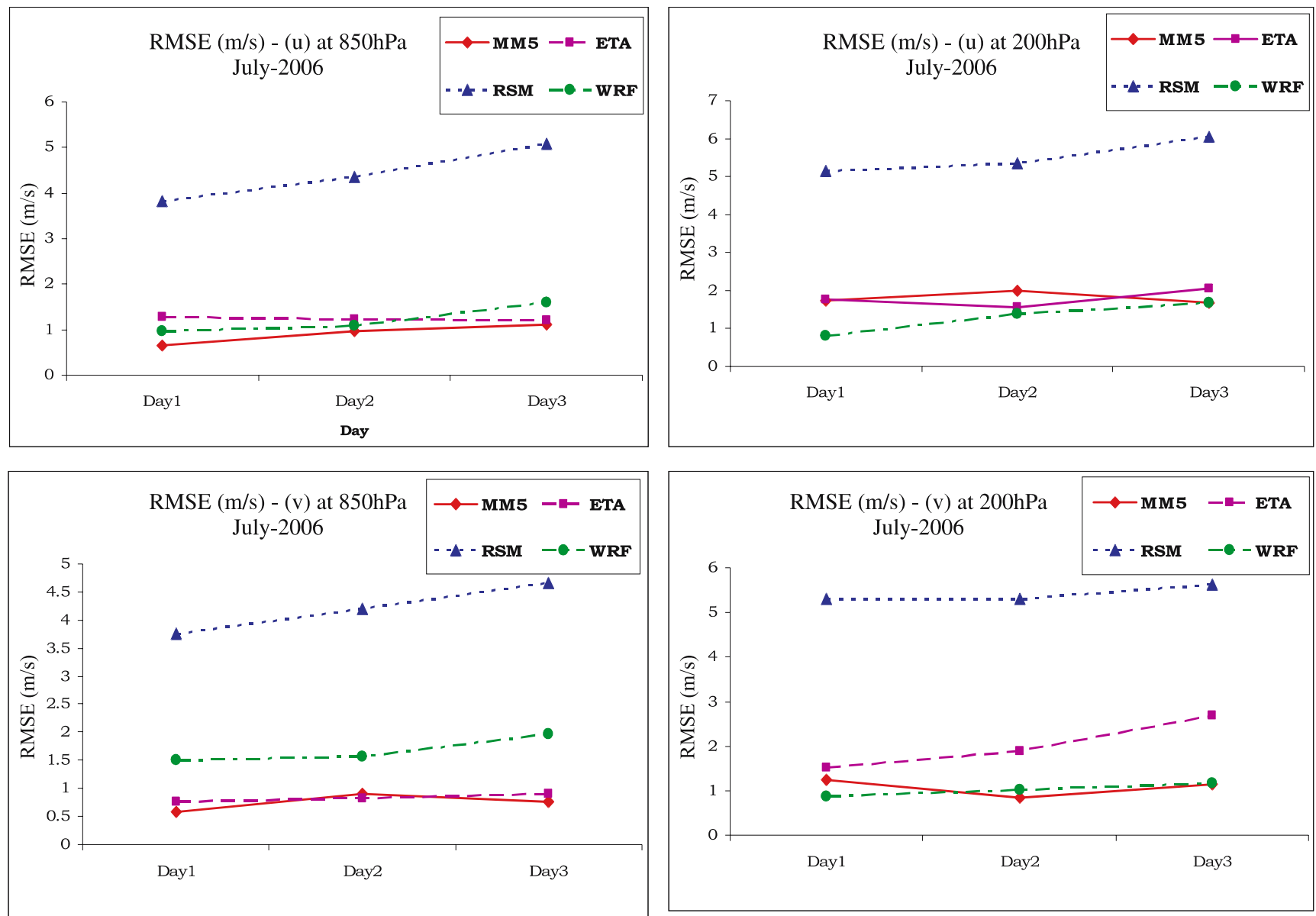

Figure 9. Root Mean Square Errors (RMSE) of zonal and meridional wind $\left(\mathrm{m} \mathrm{s}^{-1}\right)$ at $850 \mathrm{hPa}$ obtained from the four models MM5, ETA, RSM and WRF for July 2006.

the four months. MM5 produced least RMSE of day-3 forecasts most of the time. WRF produced best day-1 forecasts in July. At upper level, RSM produced least errors in day-3 forecasts of July. MM5 produced best forecasts for all three days most of the time. ETA produced better day-3 forecasts in August and September.

The RMSE of specific humidity (figure 10) indicate that RSM produced highest RMSE of specific humidity. MM5 produced best forecasts for all the 3 days in July, August and September.

\subsection{Skill of rainfall forecasts}

We have computed the threat scores (TS), false alarm ratio (FAR), and the All-India area averaged rainfall forecasts from all the models. For brevity, only two of them are presented here.

\subsubsection{Threat scores}

Figure 11 shows the equitable threat scores (ETS) of rainfall forecasts (day- 1 and day-3) for different threshold values from $0-1,1-2,2-4,4-6$,
6-8 and $8-11 \mathrm{~cm}$ rainfall obtained from the 4 mesoscale models. The ETS values are computed for eastern sector $\left(21-24^{\circ} \mathrm{N}, 85-92^{\circ} \mathrm{E}\right)$ and western sector $\left(15-24^{\circ} \mathrm{N}, 70-75^{\circ} \mathrm{E}\right)$, which are the heavy rainfall zones during the Indian summer monsoon. The scores have been computed with respect to observed rainfall merged with TRMM. Results show that the models have relatively better skills in predicting the rainfall up to $2-4 \mathrm{~cm}$ over the western sector, while on the eastern sector; some of the models have also skills for predicting up to 4-6 cm rainfall. For the light and medium rainfall categories (up to $4 \mathrm{~cm}$ ), MM5 has the highest skill both over the eastern and western sectors followed by RSM, ETA and WRF. For heavy rainfall categories $(4-6 \mathrm{~cm})$, the ETA model shows better skill over both eastern and the western sectors. None of the models showed skills in forecasting very heavy rainfall categories $(6-11 \mathrm{~cm})$.

\subsubsection{All India area averaged rainfall}

Figure 12 presents the All India area averaged observed rainfall $(\mathrm{cm})$ after merging rain gauge 

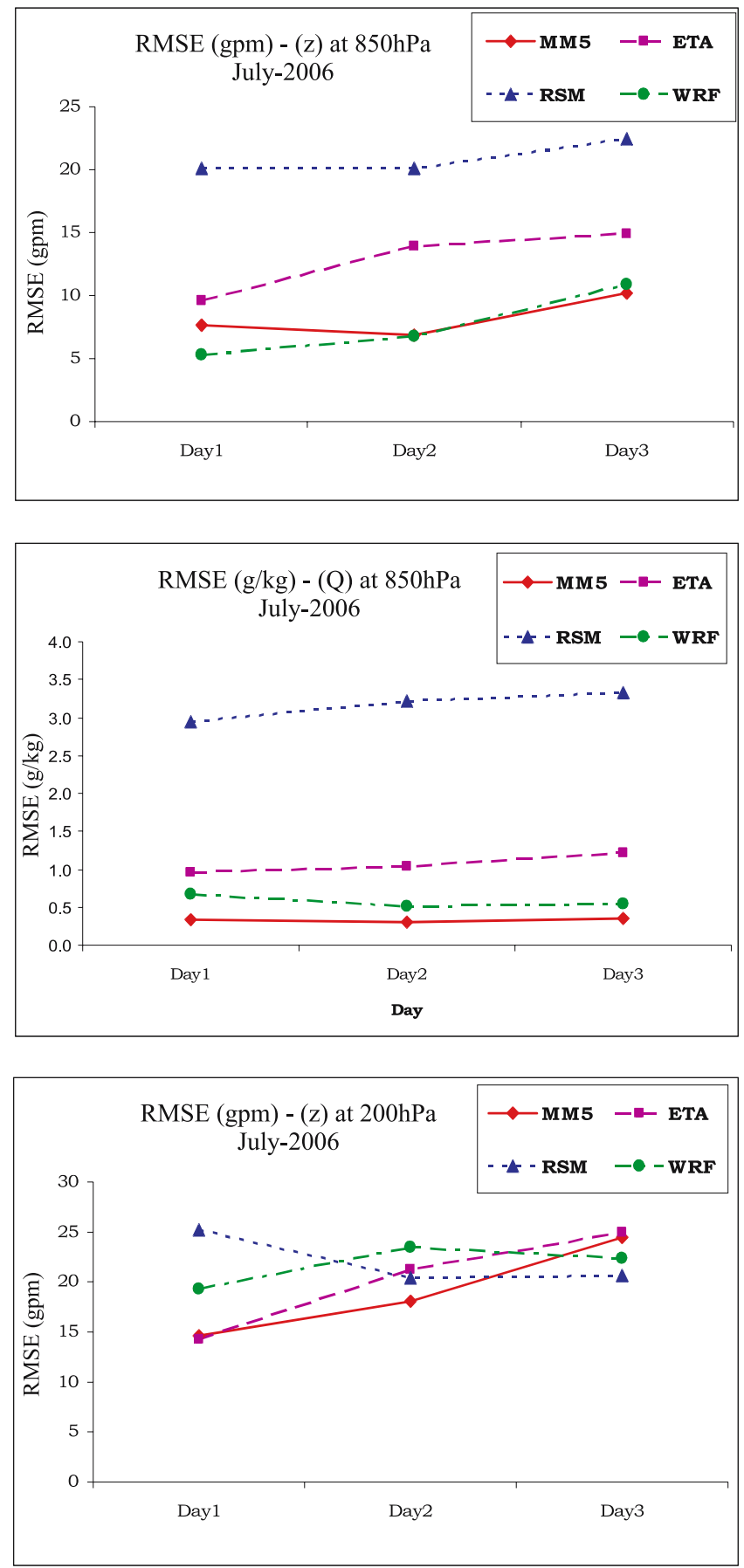

Figure 10. As in figure 9 but for the geopotential height (m) and specific humidity $\left(\mathrm{g} \mathrm{kg}^{-1}\right)$.

with TRMM values for the months of June, July, August and September and the forecasts (day-1 and day-3) obtained from the 4 mesoscale models. It also presents combined JJAS observed and predicted rainfalls from the four models. Results indicate that MM5 produced best All India area averaged in day-1 forecasts of June, July and August and in the day- 3 forecasts of all the four months. ETA produced best day-1 forecasts in the month of September. Further analysis indicate that while the MM5, RSM and WRF overestimate the rainfall in their day-1 forecasts for June, August and September, the ETA model underestimates the rainfall in all the four months. Analysis of day-3 forecasts indicate the rainfall is overestimated by MM5, ETA and RSM in July. MM5 underestimates the rainfall in June, August and September, while WRF underestimates the rainfall in all the four months. The combined JJAS rainfall shows that the best day- 1 and day- 3 forecasts were produced by the MM5 model compared to observations.

\section{Summary}

The performance of four mesoscale models namely, the MM5, ETA, RSM and WRF run at NCMRWF have been examined during monsoon-2006. The mean monthly analyses, systematic errors of wind fields, temperature, specific humidity and the rainfall forecasts obtained from the four models have been examined for all the four months June, July, August and September (JJAS). The models have also been evaluated for their performance during specific events like the monsoon depressions, forecasts of their tracks, circulation fields and rainfalls. Root mean square errors of the day-1, day-2 and day-3 forecasts of zonal wind, meridional wind, geopotential and specific humidity fields have been examined for all the four months. Threat scores of rainfall forecasts have been computed for different threshold values. The All-India area averaged forecasts of rainfall have been compared with rain gauge observations merged with satellite (TRMM).

This is a first attempt to make a detailed investigation of the performance of four different mesoscale models over the Indian region. All four models produce errors and biases in the forecast fields in different ways. Many issues remain to be addressed as to why a model performs in a particular way? In order to address such issues, many sensitivity experiments will have to be carried out, which is beyond the scope of this paper. The most difficult question to answer is which model among the four performs best over the Indian region? An honest answer is 'none'. As seen from the detailed analyses above, the models produce mixed performances. Therefore, in such a situation an ensemble approach is recommendable. Further, as the configurations of the four models are different in terms of resolutions, vertical layers, and choices of physical parameterization schemes, we should not expect to answer the question of which is the best model among the four. Moreover, skills of the mesoscale models are controlled by the skill of the global model, which provides its initial and boundary conditions. Therefore, if the mesoscale 


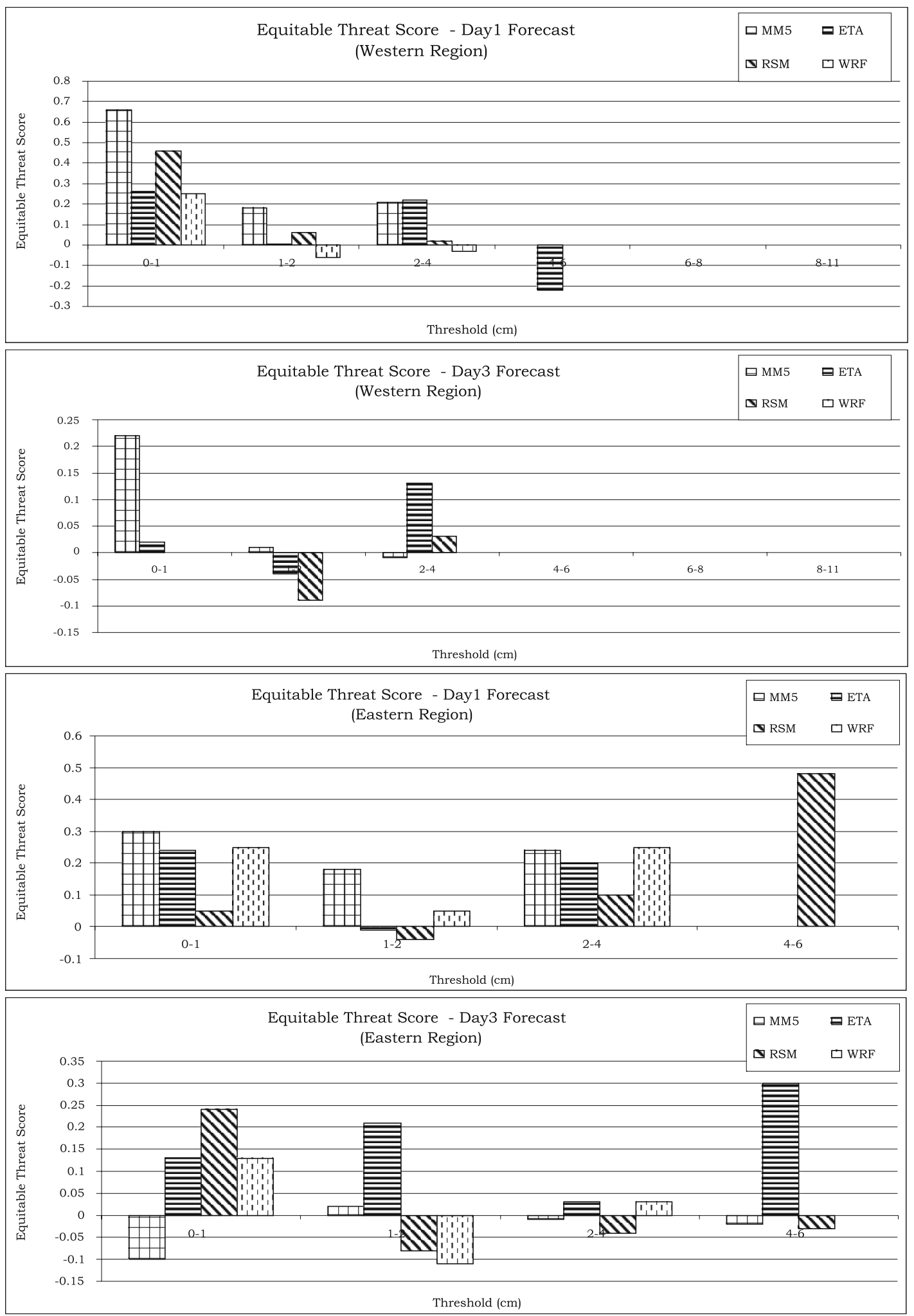

Figure 11. Equitable Threat Scores of rainfall for threshold values $0-1,1-2,2-4,4-6,6-8$ and $8-11 \mathrm{~cm}$ over western and eastern regions for day-1 and day-3 forecasts during JJAS.

models are not performing well, they should not alone be blamed.

The foregoing analyses indicate that while the MM5 and WRF models have relatively better skills in quantitative precipitation forecasts, the ETA and RSM are good in producing least track errors of monsoon depressions. The most challenging task is how to reduce errors in the forecasts. Since the 

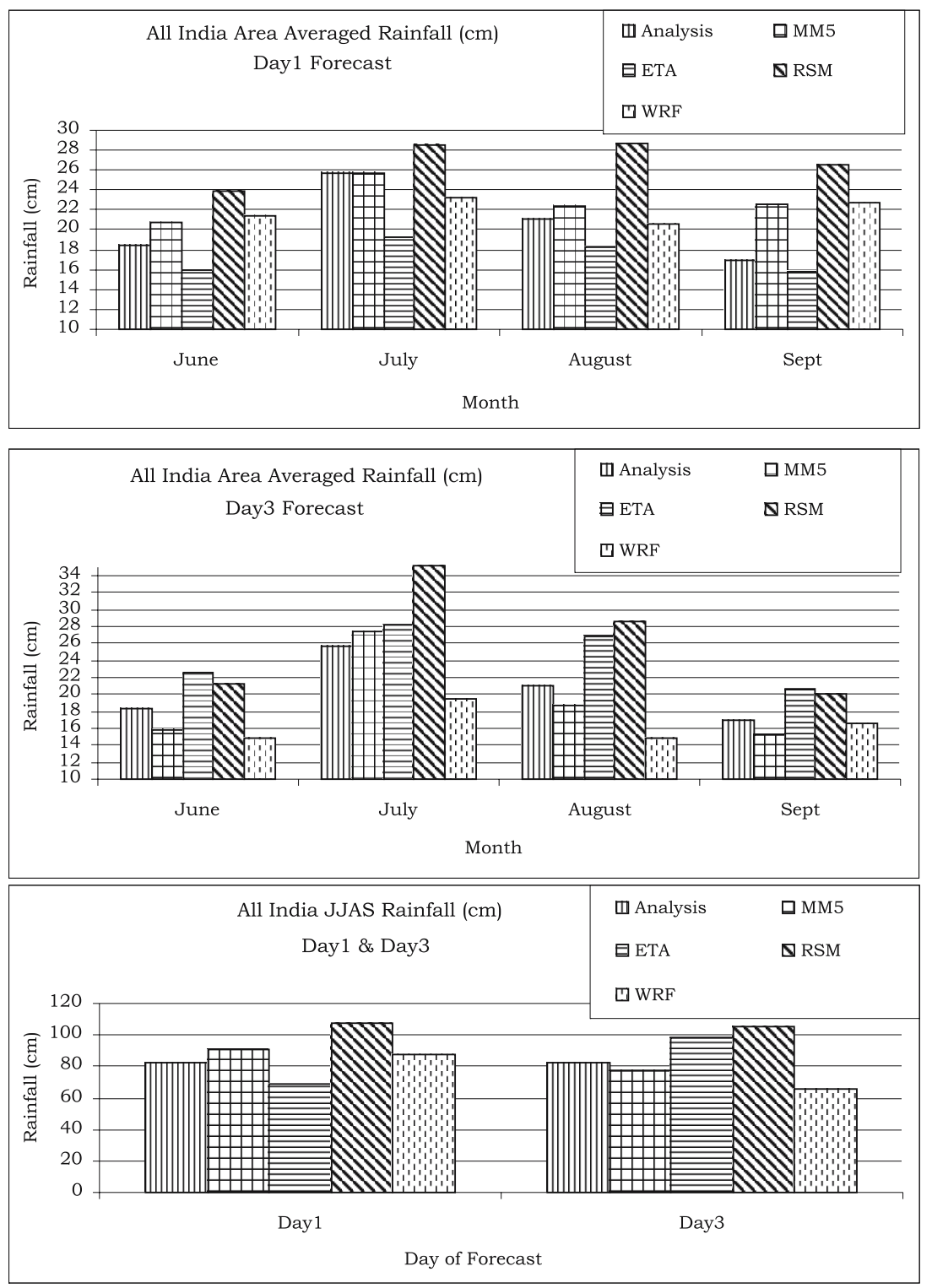

Figure 12. All India averaged rainfall $(\mathrm{cm})$ obtained from analysis, MM5, ETA, RSM and WRF models for day-1 and day-3 forecasts of June, July, August, September and JJAS.

forecasts are very sensitive to the initial and boundary conditions, an obvious first choice is to examine whether we can produce better initial conditions by assimilating more observations at mesoscale resolution in the model. With this view, we have studied the effects of mesoscale data assimilation in the short range forecasts for the entire monsoon period of 2006. The results of this study are presented in Das et al (2007).

\section{Acknowledgements}

First of all we would like to thank NCAR for making the MM5 and WRF models available along with the 3DVAR and, NCEP for the ETA and RSM models. We would like to thank the
Head, NCMRWF for his support in this study. We are grateful to IMD for providing the daily rain gauge observations of monsoon-2006. We thank Drs D R Sikka, A K Mitra and S C Kar for reviewing the full report of this paper and providing valuable comments. Thanks are also due to Mr. Jagvir Singh for providing the dates of monsoon lows and depressions of 2006 and Mr. Prabodha Pradhan for merging the rainfall data with TRMM observations.

\section{List of Acronyms}

ARPS : Atmospheric Regional Prediction System

ARW : Advance Research WRF 
CEF

: Cross Equatorial flow

COAMPS : Coupled Ocean Atmospheric Mesoscale Prediction System

ETA : ETA coordinate regional model

ETS : Equitable Threat Score

GFDL : Geophysical Fluid Dynamics Laboratory

FAR : False Alarm Ratio

IAF : Indian Air Force

IMD : India Meteorological Department

JJAS : June, July, August and September

LW : Long Wave

MRF : Medium Range Forecast

MM5 : 5th generation Mesoscale Model

NCAR : National Centre for Atmospheric Research

NCEP : National Centre for Environmental Prediction

NCMRWF : National Centre for Medium Range Weather Forecasting

NMM : Non-hydrostatic Mesoscale Model

NWP : Numerical Weather Prediction

RMSE : Root Mean Square Model

RRTM : Rapid Radiation Transfer Model

RSM : Regional Spectral Model

SASE : Snow \& Avalanche Study Establishment

STORM : Severe Thunderstorm Observation \& Regional Modelling

SW : Short Wave

TRMM : Tropical Rainfall Measuring Mission

TS

$\mathrm{T} 80$

- Threat Score

UKMO : UK Meteorological Office

USGS : United States Geological Survey

YSU : Yon-si University

WRF : Weather Research \& Forecasting

WSM : WRF Single Moment microphysics

3DVAR : 3 Dimensional Variational

\section{References}

Abhilash S, Someshwar Das, Mohankumar K, Kalsi S R, Das Gupta M, John P George, Banerjee S K, Thampi S B and Pradhan D 2007: Assimilation of Doppler Weather Radar observations in a Mesoscale model for the Prediction of Intense Rainfall Events Associated with Mesoscale
Convective Systems using 3DVAR; J. Earth Syst. Sci. 116(3) 275-304.

Black T L 1994 The new NMC mesoscale eta model: Description and forecast examples; Wea. Forecasting 9 265-278.

Bohra A K, Basu S, Rajagopal E N, Iyengar G R, Das Gupta M, Ashrit R and Athiyaman B 2006 Heavy rainfall episode over Mumbai on 26th July 2005: Assessment of NWP guidance; Curr. Sci. 90(9) 1188-1194.

Colle B A, Westrick K J and Mass C F 1999 Evaluation of MM5 and Eta-10 precipitation forecasts over the Pacific Northwest during the cold season; Wea. Forecasting 14 $137-154$

Das Someshwar 2002a Real time mesoscale weather forecasting over Indian region using MM5 modeling system; NCMRWF Research Report No. NMRF/RR/3/2002 77 .

Das Someshwar 2002b Evaluation and verification of MM5 forecasts over Indian region; 12th PSU/NCAR mesoscale model users workshop, 24-25 June, 2002, Boulder, CO, USA 77-81.

Das Someshwar, Singh S V, Rajagopal E N and Gall R 2003 Mesoscale modeling for mountain weather forecasting over the Himalayas; Bull. Amer. Meteor. Soc. 84(9) $1237-1244$.

Das Someshwar 2005 Mountain weather forecasting using MM5 modeling system; Curr. Sci. 88(6) 899-905.

Das Someshwar, Ashrit R, Mohandas S, Iyengar G R, Das Gupta M, George J P, Rajagopal E N and Dutta S K 2007 Performance of Mesoscale Models over India during Monsoon season; NCMRWF Research Report, 144 pp.

Davis C, Warner T, Astling E and Bowers J 1999 Development and application of an operational, relocatable, mesogamma-scale weather analysis and forecasting system; Tellus 51A 710-727.

Davis C and Carr F 2000 Summary of the 1998 Workshop on Mesoscale Model Verification; Bull. Amer. Meteor. Soc. 81 809-819.

Doswell C A III, Davies-Jones R and Keller D L 1990 On summary measures of skill in rare event forecasting based on contingency tables; Mon. Wea. Rev. 118 576-585.

Dudhia J 1993 A non-hydrostatic version of the Penn State/NCAR mesoscale model: Validation tests and simulation of an Atlantic cyclone and cold front; Mon. Wea. Rev. 121 1493-1513.

Ferranti L, Klinker E, Hollingsworth A and Hoskins B J 2000 Diagnosis of systematic forecast errors dependent on flow pattern; WCRP/WGNE Workshop on systematic errors, 16-20 October, 2000, BMRC, Australia, pp 57-60.

Grell G A, Dudhia J and Stauffer D R 1994 A description of the 5th generation Penn State/NCAR Mesoscale model (MM5); NCAR tech. note, NCAR/TN-398+STR, $117 \mathrm{pp}$.

Grimit E P and Mass C F 2002 Initial results of a mesoscale short-range ensemble forecasting system over the Pacific Northwest; Wea. Forecasting 17 192-205.

Juang H-M H and Kanamitsu M 1994 The NMC nested regional spectral model; Mon. Wea. Rev. 122 3-26.

Juang H-M H, Hong S-Y and Kanamitsu M 1997 The NCEP regional spectral model: an update; Bull. Amer. Meteor. Soc. 78 2125-2143.

Kuo Y-H 2003 Mesoscale Numerical Weather Prediction. H.D; Orville Symposium, Institute of Atmospheric Science, SDSMT, 26 April 2003, USA, pp 122-130.

Kuo Y-H and Wang W 1996 Simulation of a prefrontal rainband observed in TAMEX IOP 13; Preprints, Seventh Conference on Mesoscale Processes; Reading, U.K., 9-13 September 1996, 335-338. 
McBride J L and Ebert E E 2000 Verification of quantitative precipitation forecasts from operational numerical weather prediction models over Australia; Wea. Forecasting 15 103-121.

Mesinger F 1996 Improvements in quantitative precipitation forecasts with Eta regional model at the National Centers for Environmental Prediction: The 48-km upgrade; Bull. Amer. Meteor. Soc. 77 2637-2649.

Mitra A K, Das Gupta M, Singh S V and Krishnamurti T N 2003 Daily Rainfall for Indian Monsoon Region from Merged satellite and Rain-Guage Values: Large-Scale Analysis from Real Time data"; J. Hydrometeor. 4 769-781.

Mohandas S and Rajagopal E N 2005 Sensitivity of landsurface parameterization on regional spectral model forecasts; Curr. Sci. 88(6) 935-941.

Mureau R 1990 The decrease of the systematic error and the increased predictability of the long waves in the ECMWF model; ECMWF Tech. Mem. No. $16 \%$.

NCAR 2003 PSU/NCAR Mesoscale Modeling System (MM5 version 3) tutorial class notes and user's guide. Available from the National Center for
Atmospheric Research, Boulder, Colorado, USA, June 2003.

Palmer T N 1988 Medium and extended range predictability and stability of the Pacific-North American mode; Quart. J. Roy. Meteor. Soc. 116 799-83.

Rajagopal E N and Iyengar G R 2002 Implementation of Mesoscale ETA model at NCMRWF; NCMRWF research report no. NMRF/ RR/4/2002.

Rajagopal E N and Iyengar G R 2003 Performance of Mesoscale Eta model over Indian region; Weather and Climate Modeling (eds) Singh et al (New Delhi: New Age Intl. Ltd.) $118-131$.

Rajagopal E N and Iyengar G R 2005 Mesoscale forecasts with Eta model over Indian region; Curr. Sci. 88(6) 906-912.

Srinivas C V, Venkatesan R, Muralidharan N V, Someshwar Das, Hari Dass and Eswara Kumar P 2006 Operational Mesoscale Atmospheric Dispersion Prediction using Parallel Computing Cluster; J. Earth Syst. Sci. 115(3) 315-332.

Wilks D S 1995 Statistical Methods in the Atmospheric Sciences; Academic Press, 467 pp. 